\title{
Understanding of Behavioral Problems Among Young Persons with Intellectual Disability: A Self-Report
}

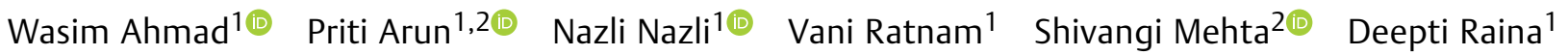 \\ ${ }^{1}$ Department of Special Education (Intellectual Disability), \\ Government Rehabilitation Institute for Intellectual Disabilities \\ (GRIID), Chandigarh, India \\ 2 Department of Psychiatry, Government Medical College and \\ Hospital, Chandigarh, India \\ Address for correspondence Wasim Ahmad, PhD, Department of \\ Special Education (Intellectual Disability), Government Rehabilitation \\ Institute for Intellectual Disabilities (GRIID), Chandigarh, India \\ (e-mail: wasimarid@gmail.com).
}

J Neurosci Rural Pract 2022;13:295-300.

\section{Introduction}

Persons with intellectual disability (ID) are said to have behavioral problems in the form of stereotypes, aggression, and violence that might lead to injury to self, to others, or destruction of property, etc. ${ }^{1,2}$ These behaviors are detrimental not only to the person himself who exhibits such behavior but pose a challenge to their teachers and caregivers. A behavior becomes challenging when it is of such intensity, frequency, or duration that it threatens the safety of self or others. It is likely to lead to restrictive or aversive responses and exclude social participation. ${ }^{3}$ Earlier studies from the west have found that $\sim 10 \%$ of persons with ID manifest severe challenging behavior ranging from self-injury, destructiveness, aggression, published online February 9, 2022
DOI https://doi.org/

10.1055/s-0042-1743213. ISSN $0976-3147$. (c) 2022. Association for Helping Neurosurgical Sick People. All rights reserved.

This is an open access article published by Thieme under the terms of the Creative Commons Attribution-NonDerivative-NonCommercial-License, permitting copying and reproduction so long as the original work is given appropriate credit. Contents may not be used for commercial purposes, or adapted, remixed, transformed or built upon. (https://creativecommons.org/ licenses/by-nc-nd/4.0/)

Thieme Medical and Scientific Publishers Pvt. Ltd., A-12, 2nd Floor, Sector 2, Noida-201301 UP, India 
and disruptive behavior. ${ }^{1,4}$ When milder forms of behavioral problems such as verbal aggression and temper tantrums are included, the prevalence goes up to 22.5 to $55 \%{ }^{5,6}$ A study from India reported that violent and destructive temper tantrums and self-injurious behavior among persons with ID vary according to its severity. ${ }^{7}$ The behavioral problem among children with ID is also shaped by the social environment in which they live and interact. ${ }^{8}$ Due to a lack of awareness and knowledge, abnormal behaviors among persons with ID might be considered manifestations of mental illness. However, the studies have also reported that behavioral problems among persons with ID increase the likelihood of occurrence of mental illness. ${ }^{9,10}$

Assessment of behavioral problems among persons with ID is very challenging due to cognitive and communication deficits. $^{2}$ The only way to assess behavioral problems of persons with ID is direct observation or report by the teachers and caregivers. ${ }^{11}$ To have accurate information from parents and teachers, several tools have been developed, such as Developmental Behavioral Checklist (DBC), the Aberrant Behavior Checklist $(\mathrm{ABC})^{12}$ and Behavioral Assessment Scale for Assessment of Children with Mental Retardation (BASIC-MR). ${ }^{13}$ Whatever information we have on behavioral problems among persons with ID is from the teachers and caregivers. A particular behavior is labeled as problematic by the people around, but no attempt has ever been made to understand the concept of problem behavior of persons with ID. The present study was planned to understand the problem behavior of persons with ID in terms of three main questions, viz, do they have a concept of problem behavior? Do they make any efforts to control these behaviors? Are they aware of how to handle such problem behaviors at their level?

\section{Materials and Methods}

For the present study, a qualitative method using focused group discussion (FGD) was employed to collect the data. These FGDs were recorded, transcribed, and analyzed. However, no formal assessment was performed to assess the behavioral problems because the purpose of the study was to understand the concept of behavioral problems from individuals with IDs. Participants were selected using a stratified random sampling method.

\section{Setting}

The study was conducted at Government Rehabilitation Institute for Intellectual Disabilities (GRIID), Chandigarh, India, an institution that has a School of Special Education, where learning is imparted through special education and vocational training aiming at making them as financially and socially independent as possible vying to integrate them into the mainstream, Clinical Services, and a College of Special Education where special educators are given training through courses such as Diploma (D.Ed.), Bachelors (B.Ed.), and Masters (M.Ed.) in Special Education (Intellectual disability). The FGDs were conducted in the conference hall of the institute. This place was chosen for easier access for the participants. It was ensured that no one other than the research team and the participants were present in the hall. The researchers had clinical, supervisory, and administrative responsibilities in the institute.

\section{Participants}

In GRIID, there are 429 persons with intellectual disabilities (PWID). In the age range of 15 to 30 years, there were around 255 PWID males (193) and females (62), out of which the mild category (IQ: 50-69) were 55, males (47) and females (8). The list of total $(n=55)$ was prepared, from which participants $(n=13)$ were selected through lottery method using the DSM 5 diagnosis of mild ID (IQ: 50-69) in the age ranging from 16 to 27 years. The essential characteristics of the participants are given below in - Table 1 .

Although this was done through random sampling, efforts were made to have equal males and females with somewhat equal representation from rural and urban backgrounds. Four participants were from rural locations, and the rest were from the urban locality. Inclusion criteria were as follows: persons with mild ID who had verbal ability to communicate (more than $80 \%$ scores based on the BASICMR and MDPS) and IQ done and certified by the trained and licensed clinical psychologist not earlier than 3 years (for $<18$ years)(In India before 18 years of age, the IQ certificate is valid only for 5 years; however, the permanent disability certificate is issued only after 18 years). Exclusion criteria were those who were on medication for psychiatric illness, had any comorbidity except cerebral palsy, or have taken any social skill training last year.

Because all participants were from the institute, their IQ was readily available in the case records, and no-repeat IQ was done. IQ certificate was obtained from the office and information on the scales used for assessing IQ was also collected. Following scales had already been used for the assessment of the IQ of the participants:

Malin's Intelligence Scale for Indian Children (MISIC) is the Indian adaptation of the Wechsler Intelligence Scale for Children that measures verbal and performance abilities of children to assess intelligence from 6 years onward. It measures six and five domains of verbal and performance, respectively, and has a reliability coefficient of $\sim 0.9$, and both the concurrent and congruent validity scores are around 0.6. ${ }^{14}$

Advanced Progressive Matrices of Ravens Progressive Matrices (RPM) test, was originally developed by Raven (1936), was used. It is designed for the age group of 12 years and above. It has 48 items in two different sets having 12 and 36 items, respectively. The administration of this test takes around 40 to 60 minutes. The items in this test are arranged from simple to complex order. This is one of the most difficult among Raven's Progressive Matrices. ${ }^{15}$

Assessment of functional communication was done using Madras Developmental Programming System (MDPS) developed by Jayachandran and Vimla (1975). MDPS is a criterion-referenced test for the assessment and program planning for children with ID between the age group of 5 and 18 years. It has 360 items grouped under 18 areas/domains, each domain having 20 items. ${ }^{16}$ The domains seven and eight 
Table 1 Sociodemographic details of participants $(n=13)$

\begin{tabular}{|l|l|l|l|l|l|l|}
\hline S. No. & Participants & IQ & Score on Communication & Gender & Age & $\begin{array}{l}\text { Area of residence } \\
\text { (Locality) }\end{array}$ \\
\hline 1 & AB & 50 & $>80 \%$ & Male & 23 & Rural \\
\hline 2 & CD & 56 & $>83 \%$ & Male & 22 & Rural \\
\hline 3 & EF & 51 & $>88 \%$ & Male & 16 & Urban \\
\hline 4 & GH & 52 & $>81 \%$ & Male & 26 & Urban \\
\hline 5 & I & 69 & $>90 \%$ & Female & 20 & Urban \\
\hline 6 & KL & 69 & $>95 \%$ & Male & 25 & Urban \\
\hline 7 & MN & 57 & $>87 \%$ & Male & 19 & Urban \\
\hline 8 & OP & 50 & $>820 \%$ & Female & 27 & Urban \\
\hline 9 & QR & 60 & $>88 \%$ & Male & 19 & Urban \\
\hline 10 & ST & 67 & $>90 \%$ & Female & 18 & Urban \\
\hline 11 & UV & 51 & $>83 \%$ & Female & 17 & Rural \\
\hline 12 & WX & 69 & $>89 \%$ & Female & 21 & Rural \\
\hline 13 & YZ & 64 & $>85 \%$ & Female & 21 & Urban \\
\hline
\end{tabular}

(20 items each) are meant for the assessment of receptive and expressive language, respectively. The domains and items are developmentally sequenced thus, domains and items are arranged in simple to complex order.

Behavioral Assessment Scale for Indian Children with Mental Retardation (BASIC-MR) is developed by Peshawaria and Venkatesan (1992). It is designed to elicit systematic information on the current level of behaviors of children with ID. The scale is suitable for the age group of 3 to 16 (or 18) years. BASIC-MR has two parts-Part A: the items included in this part assess the current level of skill behaviors in the child, while Part $B$ assesses the current level of problem/maladaptive/inappropriate behaviors of children with ID. Part A consists of 280 items grouped under 7 domains ( 40 items each), whereas Part B consists of 75 items grouped under 10 domains (varying items in each domain). ${ }^{13,16}$ The domain three of Part $A$ is about the assessment of language, wherein 40 items each are meant for receptive and expressive language.

\section{Recruitment}

The potential participants were identified and requested to take part in the research. Participants were recruited using a stratified random sampling method. Investigators explained the study's objective to the participants and their legal representative, anonymity and confidentiality were assured, and signed informed consent was obtained from all participants before the induction of the study. The consent was also taken for the audio recordings. The participants were explained about the study, procedure, and voluntary participation in the study. All approached participants $(n=13)$ participated throughout the research, and no withdrawal was noted.

\section{Procedure}

A series of four FGDs were conducted using mixed language (Hindi and Punjabi) for the convenience of the participants; however, the researchers translated the conversation into English as accurately as possible. All researchers were well trained and experienced in the field of ID. The average experience of the investigators was 13 years in the field of ID. Out of three persons who conducted the sessions, one was having a good rapport with participants. In contrast, the participants were aware that the other two are also working in the same institute though they did not have one-on-one interaction with the participants.

A proper rapport was built with the participants before leading the groups. The primary aim of the research team was to collect qualitative data on common behavioral problems among persons with ID. For this purpose, the first group session was taken with both males and females. The two FGDs were conducted by three researchers (PA and WA), and the other FGDs were conducted by (PA, WA, and SM). One of the researchers (VR) observed the whole FGD live via a computer to avoid any discomfort to the participants. The sessions were audio-recorded. The information in this paper is based on four FGDs completed within 3 weeks, each lasting for 60 to 90 minutes. The three researchers (WA for males and DR/SM for females) were assigned to record the discussion. Later, the investigators reviewed audio recording sessions to determine discrepancies, if any.

The researchers (WA and PA) leading the group encouraged interaction and ensured that all participants contributed at their best. The researcher (WA) took notes, identified significant themes based on the discussion. To maintain uniformity, achieve objectivity, and avoid biases, two investigators rechecked the noted/recorded notes independently. Although the written copy of the FGDs was not given to the participants, a summary was shared with them.

\section{Discussion Guide}

A discussion guide was made by the research team that covered the concept, and a range of problem behaviors was prepared. The guide consisted of three themes: (1) the 
concept of problem behavior (what is problem behavior?, what are the various problem behaviors?, is it different from the behavior of others?, can it be decreased? and If yes! how and why?), (2) do they make any efforts to control these behaviors? (3) how one can avoid indulging in such problematic behaviors? The FGDs were conducted in such a manner that participants were free, comfortable, and motivated to respond to the asked questions exploring their concepts, perceptions, and experiences about behavior problems. The study was approved by the research and ethics committee of the institute.

\section{Results}

The noted records were read and re-read independently by the two investigators (PA and WA) to identify the emerging themes. Later, the summary was distributed among all the researchers to counter-check if there is any point being left. The mean IQ of the participants was 52.84, and the mean age was 21.0 years. The group had seven male and six female participants. The comments of the participants during the discussion have been mentioned without disclosing the identity of the participants. The identified themes for the discussions are mentioned and presented below:

\section{Concept of Problem Behavior}

The discussion was initiated by asking an open-ended question: "What is problem behavior?" The group stated that "Any behavior that others find bad is abnormal behavior." The group further identified that behaviors such as laughing at others, making fun of others, hitting others, snatching food, roaming around aimlessly in the classes and the school, twisting facts, making false complaints, kissing, touching girls, loose talk (will you marry me) and masturbation are all problem behaviors. One of the participants (AB) stated, "When someone hits my friend, I support my friend." After this statement, the research team attempted to understand their concept of friendship. The group was asked, "What makes a person a good friend, and on what basis can a person be called a good friend"? The group stated (led by WX) that "A person who shares his articles with others and speaks truth is a good friend." Similar opinions were made by the other two participants (EF and ST).

\section{Do They Make any Efforts to Control these Behavioral Problems?}

The participants felt the need to control their anger, and when asked, "what do you do to control your anger?" One participant (CD) shared that "Whenever I get angry, I control my anger by having a glass of water or juice, eating food of my choice, listening to music, or going out to play." The participant displayed good coping behavior to control his anger. They were also aware of the consequences of not suppressing the urge to use physical aggression, which they could use successfully. One of the participants (OP) shared that "When we are in the school bus, there are some naughty boys who disturb others by kissing others, pulling or snatching articles from others; I feel like beating such boy, but I am afraid that they would complain to my teacher or school principal." "I believe yoga also helps in controlling anger. I have seen my mother suggesting her friend go for yoga when she is getting angry. I do practice Yoga in such situations" was added by another participant $(\mathrm{GH})$.

\section{How Can One Avoid Indulging in Such Behavioral Problems?}

The response received from the participants were "It is always good to avoid such company where there are chances of getting involved in the behavioral problems" (IJ)." One of the participants $(\mathrm{QR})$ shared that his mother always asks him, "Not to play with some of my neighbors as they easily get into quarrels, fights, and abuses." "One should avoid making friends with such people who drink, smoke, chew tobacco" above was expressed by another participant (MN). One of the participants (KL) shared a recent experience, and he added that "There are people involved in stealing. We need to keep ourselves away from such persons. There is one student who tries to kiss me, but I always maintain distance from him. I have stopped sitting, having lunch, and playing with him just because of his behavior. My teacher on my complaints has already scolded him. I have reported this matter to my sports teacher also. The teacher has promised me that if he repeats the same mistake in the future, she will not allow him to play." "I play with my brother instead of playing with my neighbors because he fights with me for no reasons," was added by UV.

\section{Discussion}

If it is compared, the behavioral problems exhibited by individuals with ID and their methods to control anger and aggression will not be very different from those without disabilities. A study reported that students with IDs were found to have a good self-concept, goal orientation, and selfregulation compared with students with physical disabilities. ${ }^{17}$ However, the social participation of persons with disabilities is not only dependent upon individual functionality but is primarily influenced by public attitudes toward disability. ${ }^{18}$ A study from India reported that cultural and religious beliefs negatively affect disability. ${ }^{19}$ A recent World Health Organization report on disability recommends increasing the community participation of persons with disabilities, should augment public awareness and understanding of disability. ${ }^{20}$ The readers of this article may find the participants' level of understanding like the usual understanding of this age group. Before moving further, it is essential to clarify this point. DSM 5 describes ID as "impairment of general mental abilities that impact adaptive functioning in conceptual, social, and practical domains." One of the significant limitations of this definition is that the condition is described as a single entity like any other disorder. The fact is that adaptive functioning depends upon the level of intellectual capacity. There may not be a significant visible deficit in a milder form, whereas the severe and profound forms of ID are likely to have substantial 
deficits in adaptive functioning. ${ }^{21}$ The prevalence of ID in the United States and other developed countries is consistently in the range of 2.5 to 5 per 1,000 children; mild ID ranges from as low as 2 to more than 30 per $1,000 .{ }^{22,23}$ Most persons with mild ID are slower in conceptual development and social and daily living skills. However, they can learn practical life skills, which allow them to function in ordinary life with minimal levels of support. ${ }^{24}$ Persons with mild ID can lead a successful life with little support as and when required. ${ }^{25,26}$

The authors of the present study wish to highlight that with intermittent support person with mild ID can lead a successful life. Their lifestyle can be very close to ordinary people, provided they are given appropriate training and opportunities. Even within mild ID, persons having IQs between 60 and 70 participated more actively than those with 50 and 60 during FGDs.

The findings were shared with the participants seeking their feedback and comments. It was interesting to note that the participants agreed with the conclusions given. Persons with mild ID have sufficient insight into their behavioral problems and control their anger and aggression. It is an underestimation of their ability by society that they do not have meaningful insight into their behavioral issues and strategies to overcome them. Persons with ID can make their own choices, solve their problems, participate in community activities, and decide what is good for them, provided they are given the opportunity. ${ }^{27}$ Persons with ID are likely to set meaningful goals and make choices for themselves when they are self-determined, i.e., the ability to make choices, solve problems, and make correct decisions. ${ }^{28}$ Appropriate training may help empower persons with ID, and this empowerment can contribute to social inclusion and better quality of life. ${ }^{29}$ If persons with IDs are allowed to participate in the community, there is a possibility of developing a greater self-concept followed by quality of life. ${ }^{30,31}$

\section{Conclusion}

The collection of data was directly from persons with ID, which must be viewed as its strength as there have been limited studies conducted in past on understanding the concept of behavioral problem from the perspective of persons with ID. The views expressed were of persons with ID and not of their teachers/caregivers, which must be taken into account. The present study has tried to explore the perspective of persons with IDs toward behavioral problems. Several studies have been conducted on behavioral problems among persons with IDs. Still, only a limited study has been conducted where persons with ID are asked to talk about it from their perspective. The findings of this study may give insight to the researchers to conduct research allowing persons with ID to speak about their concerns, issues, and challenges in their day-to-day life. The study also highlights the awareness among persons with ID about behavioral problems and strategies to handle and overcome the same.
Funding

None.

Conflict of Interest

None declared.

\section{Acknowledgments}

The authors are grateful to the late Dr. BS Chavan, Formerly Director Principal, Government Medical College, and Hospital (GMCH), Chandigarh and Director, Government Rehabilitation Institute for Intellectual Disabilities (GRIID), Chandigarh, for conceiving this project and guiding throughout. The authors also would like to thank all the participants for their active and meaningful participation in this project. The immense help received from the scholars whose articles are cited and included in this manuscript's references is also acknowledged.

\section{References}

1 Lowe K, Allen D, Jones E, Brophy S, Moore K, James W. Challenging behaviours: prevalence and topographies. J Intellect Disabil Res 2007;51(Pt 8);625-636

2 Smith KR, Matson JL. Behavior problems: differences among intellectually disabled adults with co-morbid autism spectrum disorders and epilepsy. Res Dev Disabil 2010;31(05):1062-1069

3 Royal College of Psychiatrists. British Psychological Society \& Royal College of Speech and Language Therapists. (2007) Challenging behaviour: a unified approach. College Report CR144. Accessed August 15, 2020 at: https://www.rcpsych.ac.uk/docs/defaultsource/improving-care/better-mh-policy/college-reports/collegereport-cr144.pdf?sfvrsn=73e437e8_2

4 Emerson E, Kiernan C, Alborz A, et al. The prevalence of challenging behaviors: a total population study. Res Dev Disabil 2001;22 (01):77-93

5 Deb S, Joyce J. Psychiatric illness and behavioural problems in adults with learning disability and epilepsy. Behav Neurol 1999; 11(03):125-129

6 Cooper SA, Smiley E, Morrison J, Williamson A, Allan L. Mental illhealth in adults with intellectual disabilities: prevalence and associated factors. Br J Psychiatry 2007;190:27-35

7 Lakhan R, Kishore MT. Behaviour problems in children with intellectual disabilities in a resource-poor setting in India - part 1: association with age, sex, severity of intellectual disabilities and IQ. J Appl Res Intellect Disabil 2018;31(01):43-50

8 Lakhan R. Effect of play and exposure on development of children with intellectual disabilities through community-based rehabilitation. Indian Journal of Physical Medicine and Rehabilitation 2009;20(01):13-18

9 Grey IM, Hastings RP. Evidence-based practices in intellectual disability and behaviour disorders. Curr Opin Psychiatry 2005;18 (05):469-475

10 Rojahn J, Matson JL, Naglieri JA, Mayville E. Relationships between psychiatric conditions and behavior problems among adults with mental retardation. Am J Ment Retard 2004;109(01):21-33

11 Kerr MP. Behavioral assessment in mentally retarded and developmentally disabled patients with epilepsy. Epilepsy \& behavior: E\&B 2002;3(6S1):14-17

12 Aman MG, Burrow WH, Wolford PL. The Aberrant Behavior Checklist-Community: factor validity and effect of subject variables for adults in group homes. Am J Ment Retard 1995;100(03): 283-292(AJMR)

13 Peshawaria R, Venkatesan S. Behavioral Assessment Scale for Assessment of Children with Mental Retardation (BASIC-MR). Secunderabad: NIMH; 1992 
14 Venkatesan S. Celebrating a century on form boards with special reference to Seguin Form Board as measure of intelligence in children. Global Journal of Interdisciplinary and Social Sciences 2014;3(06):43-51

15 Raven J. The Raven Progressive Matrices: a review of National Norming Studies and Ethnic and Socioeconomic Variation within the United States. J Educ Meas 1989;26(01):1-16

16 Venkatesan S. Children with developmental disabilities: a training guide for parents, teachers and caregivers. New Delhi: Sage Publications; 2004

17 Varsamis P, Agaliotis I. Profiles of self-concept, goal orientation, and self-regulation in students with physical, intellectual, and multiple disabilities: Implications for instructional support. Res Dev Disabil 2011;32(05):1548-1555

18 Rees LM, Spreen O, Harnadek M. Do attitudes towards persons with handicaps really shift over time? Comparison between 1975 and 1988. Ment Retard 1991;29(02):81-86

19 Edwardraj S, Mumtaj K, Prasad JH, Kuruvilla A, Jacob KS. Perceptions about intellectual disability: a qualitative study from Vellore, South India. J Intellect Disabil Res 2010;54(08):736-748

20 WHO. World report on disability. GenevaWorld Health Organization2011. Accessed August 14, 2020 at: https://www.who. int/disabilities/world_report/2011/report.pdf?ua $=1$

21 DSM V; 2013. Accessed August 15, 2020 at: https://cdn.websiteeditor.net/30f11123991548a0af708722d458e476/files/uploaded/DSM\%2520V.pdf

22 Durkin M, Schupf N, Stein Z, Susser MM. Mental retardation. In: R Wallace, ed. Public Health and Preventive Medicine Stamford. CT: Appleton \& Lange; 2007:1173-1184

23 Maulik PK, Mascarenhas MN, Mathers CD, Dua T, Saxena S. Prevalence of intellectual disability: a meta-analysis of population-based studies. Res Dev Disabil 2011;32(02):419-436
24 National Academies of Sciences, Engineering, and Medicine 2015. Mental Disorders and Disabilities Among Low-Income Children. Washington, DC: The National Academies Press. Available at: https://doi.org/10.17226/21780

25 Khan HH, Pathan SY, Ahmad W. Factors responsible for sense of self-efficacy, self-esteem, self-confidence, and self-determination among persons with disabilities. In: Ahmad W, Chavan BS, Gupta RK, eds. Comprehensive Textbook on Disability. New Delhi, India: Jaypee Brothers Medical Publishers; 2022:453-459

26 Ahmad W, Parween S. Managing behavioural/emotional problems in inclusive classrooms and understanding the best practices. In: Singh A, Yeh CJ, Blanchard S, Anunciação L, eds. Handbook of Research on Critical Issues in Special Education for School Rehabilitation Practices. United Sattes: IGI Global; 2021:443-461

27 Ahmad W, Thressiakutty AT. Developing self determination through audio visuals among individuals with intellectual disability. Journal of Disability Management and Special Education 2012;2(01):52-63

28 Ahmad W, Thressiakutty AT. Effect of teacher's training on enhancing self-determination among individuals with intellectual disability. Indian J Soc Psychiatry 2018;34(01):16-20

29 Morisse F, Vandemaele E, Claes C, Claes L, Vandevelde S. Quality of life in persons with intellectual disabilities and mental health problems: an explorative study. The Scientific World Journal; 2013 (ePub ahead of Print). Doi: 10.1155/2013/491918

30 Ahmad W, Thressiakutty AT. Developing concept of transition planning and self-determination among special educators for their students with intellectual disability. Delhi Psy Journal 2020;23(02):391-397

31 Vashishta N. Nazli, Ahmad W. Self-concept among adults with intellectual disability in relation to quality of life. Int J Indian psychol 2020;8(03):328-336 